\title{
Doxycycline and Coenzyme Q10 Treatment Modalities for Chronic Periodontitis: A Preliminary Study
}

\author{
Mahmoud Darweesh', Hesham El-Sharkawy', Omar N Fadhil² and Ola M Maria ${ }^{3,4 *}$ \\ ${ }^{1}$ Department of Oral Medicine and Periodontology, Faculty of Dentistry, Mansoura University, Egypt \\ ${ }^{2}$ Department of Prosthodontics, Faculty of Dentistry, University of Malaya, Kuala Lumpur, Malaysia \\ ${ }^{3}$ Department of Oncology, Faculty of Medicine, McGill University, Canada
}

${ }^{4}$ Department of Oral Biology, Faculty of Dentistry, Mansoura University, Egypt

*Corresponding author: Ola M Maria, DMD, PhD, Postdoctoral Fellow, Department of Oncology, Faculty of Medicine, McGill University, Montreal, 1650 Cedar Avenue, Room L5-112, Montreal, Quebec, H3G 1A4, Canada, Tel: +1 514934 1934, Fax: +1 514934 8229, E-mail: ola.maria@mail.mcgill.ca

\begin{abstract}
Objective: Periodontitis represents one of the main causes of teeth loss. In this preliminary study, we aimed to evaluate the efficacy of different modalities for treatment of chronic periodontitis.

Method and Materials: 40 patients were divided into 4 groups: group I, received subantimicrobial dose doxycycline (SDD; 20mg) and standard scaling and root planning (SRP); group II, received Co enzyme Q10 (CoQ10; 30mg) and SRP; group III, received both drugs and SRP; group IV, received SRP only. Medications were administered twice/day for 3 months. Gingival, plaque and bleeding indices, probing pocket depth, clinical attachment level and Osteocalcin level in gingival crevicular fluid (GCF) were assessed.

Results: A combination of SDD and CoQ10 showed the best therapeutic effect $(P<0.05)$ compared to other modalities. Treatment with SDD or CoQ10 improved significantly $(P<0.05)$ the clinical parameters when compared to SRP alone. No significant reduction or increase in GCF osteocalcin level was evident.

Conclusion: Combination of SDD and CoQ10 drugs that were given twice per day for 3 months is of promising clinical outcomes. However, long-term studies on a larger number of patients are recommended to confirm or refute these findings and to explore the exact role of osteocalcin in periodontitis and its treatment modalities.

\section{Keywords}

Bleeding index, Chronic periodontitis, Clinical attachment level, Coenzyme Q10, Doxycycline, Gingival crevicular fluid, Osteocalcin, Plaque index, Probing pocket depth, Standard scaling, Root planning
\end{abstract}

\section{Introduction}

Periodontal diseases are inflammatory disorders that affect 10$15 \%$ of the population worldwide and represent one of the major causes of tooth loss. Such diseases result from complex interactions between periodontal pathogens and the host immune response
[1]. Owing to the high prevalence, scientists have been attracted to research aimed to treat periodontal diseases; however, treatments are always challenging [2]. Conventional treatment of periodontitis focused on reducing the pathogens by standard scaling and root planning, improving oral hygiene, and if needed, periodontal surgery [3]. In addition, host modulatory therapy (HMT) has been emerged as a treatment concept that aims to reduce tissue destruction and stabilize or even regenerate the periodontium by modifying or down regulating the host immune response [4]. HMT is systemically or locally delivered pharmaceuticals that are prescribed as a part of periodontal therapy and used as an adjunct to conventional periodontal treatment [5].

The tetracycline analog, doxycycline hycalate, is a collagenase inhibitor that is used to treat many human diseases [6]. It is used in low dose formulation that has no antimicrobial activity, and it acts as a host modulatory agent [7]. This non-antimicrobial action include the inhibition of tissue destruction by direct inhibition of Matrix Metalloproteinases (MMPs) [8] in the gingival tissues, inhibition of bone resorption by regulation of MMPs released by osteoclasts [9] and inhibition of MMPs precursors activation [10]. The host modulatory effects of sub-antimicrobial dose doxycycline (SDD) have been stated by several clinical studies [11-13]. SDD has been used as an adjunct to standardscaling and root planning (SRP) for the management of periodontal diseases for different treatment periods. Some studies declared significant improvements over those achieved by standard scaling alone $[14,15]$. Moreover, the long-term use of SDD has been shown to be safe and not associated with the development of antibiotic resistance in the periodontal microbial flora [16].

A second host modulatory agent is the Coenzyme Q10 (CoQ10) that has shown clinical benefits in the treatment of periodontal diseases. An adequate supply of CoQ10 to cells ensures efficient energy production, tissue oxygenation, and repair of periodontal tissues [17]. CoQ10 had a favourable effect on the endothelium of the blood vessels when it was administered at a dose of $30 \mathrm{mg}$ daily

\section{CIinMed International Library}

Citation: Darweesh M, El-Sharkawy H, Fadhil ON, Maria OM (2015) Doxycycline and Coenzyme Q10 Treatment Modalities for Chronic Periodontitis: A Preliminary Study. Int J Oral Dent Health 1:014

Received: July 07, 2015: Accepted: August 10, 2015: Published: August 13, 2015 Copyright: @ 2015 Darweesh M. This is an open-access article distributed under the terms of the Creative Commons Attribution License, which permits unrestricted use, distribution, and reproduction in any medium, provided the original author and source are credited. 
[18]. Babbush et al. [19] studied the effect of brushing with CoQ10containing toothpaste (Perfect smile tooth paste, made in USA by perfect smile corporation) in alleviating periodontal diseases. After 8 weeks, $66.6 \%$ of their patients showed significant reduction of moderate gingivitis.

Osteocalcin, a vitamin $\mathrm{K}$ dependent and calcium binding protein, is the most abundant non-collagenous protein of bone matrix that constitutes $1-2 \%$ of the total bone proteins [20]. A strong correlation between osteocalcin levels in Gingival Crevicular Fluid (GCF) and active bone turnover has been reported [21]. GCF osteocalcin level was reported to significantly correlate with the mean probing depth in postmenopausal women [22]. Moreover, chronic periodontitis patients were reported to exhibit significantly higher salivary osteocalcin levels compared to healthy controls [23]. However, Golub et al. [24] reported that, treatment of chronic periodontitis with SDD failed to reduce osteocalcin level in GCF of their patients. These controversial data indicates that the relationship of osteocalcin level in GCF and periodontitis needs further evaluation. Therefore, this study was designed to: 1) Evaluate the systemic effect of subantimicrobial dose doxycycline versus Co enzyme Q10 in conjunction with standard scaling and root planning in the treatment of chronic periodontitis. 2) Evaluate the combination of subantimicrobial dose doxycycline and coenzyme Q10 as an adjunctive therapy to standard scaling and root planning in the treatment of chronic periodontitis. 3) Assess osteocalcin level in gingival crevicular fluid in response to each treatment modality.

\section{Materials \& Methods}

\section{Patients' recruitment}

This study was conducted in the period from January 2011 to February 2012. This study followed the Declaration of Helsinki on medical protocol and ethics and was approved by the regional Ethical Review Board of Mansoura University. After fulfilling inclusion/ exclusion criteria (Figure 1), 40 patients (26 males and 14 females) were recruited from those who attended to the Oral Medicine and Periodontology Department Clinic, Faculty of Dentistry, Mansoura University to be the participants in this study. Initially, 74 chronic periodontitis patients were interviewed for enrolment (Figure 1), however, after analysis of their medical reports and history, only 40 patients were eligible to include in this study. Inclusion criteria were as follows; chronic periodontitis, age above 18 years old, patient's cooperation and motivation. Exclusion criteria were as follows; younger than 18 years old, pregnancy, smoking, parafunctional habits, bisphosphonates use, alcohol abuse; acute or chronic systemic disorders, such as; diabetes, hemorrhagic disorders cardiovascular, kidney, liver diseases, Alzheimer's disease and other conditions that might affect wound healing responses or interfere with the treatment or affect the patient's compliance. All participants were informed about the objectives and methodology of this study and an informed consent was signed by each participant before conducting this study. Their age ranged from 37 to 55 years (mean: $46.9 \pm 5.7$ ). They were diagnosed with chronic periodontitis according to the criteria of Armitage [25]. Participants were randomly classified into 4 groups; each has 10 patients as follows:

Group I included patients to be treated with standard SRP plus 20mg doxycycline twice/day for 3 months. Group II included patients to be treated with standard SRP plus 30mg CoQ10 (BioMérieux, France.) twice/day for 3 months. Group III included patients to be treated with standard SRP plus the same dose of both drugs together for 3 months. Group IV included patients to be treated with standard SRP only, this was considered as a control group. Standard scaling and root planning was performed using hand instruments and ultrasonic instruments (Hu-Friedy EMS Piezon', Chicago, IL, US). Owing to the randomization in assigning the patients into the 4 groups, it is noticed that all the participants showed generalized moderate $(>3<5$ $\mathrm{mm}$ CAL) periodontitis except for 3 patients who were assigned in group I; these 3 patients showed generalized severe ( $\geq 5 \mathrm{~mm} \mathrm{CAL}$ ) periodontitis.

\section{Collection of gingival crevicular fluid samples}

For samples use, we received approval from the Institutional Review Boards at Mansoura University. Patients of the 4 groups were prepared for sampling by removal of supra-gingival plaque and calculus. Teeth surfaces were cleaned from blood and debris dried using air syringe and isolated from saliva using cotton rolls. The samples were collected using standardized sterile paper strips. Each sterile paper strip was inserted into the gingival crevice of the

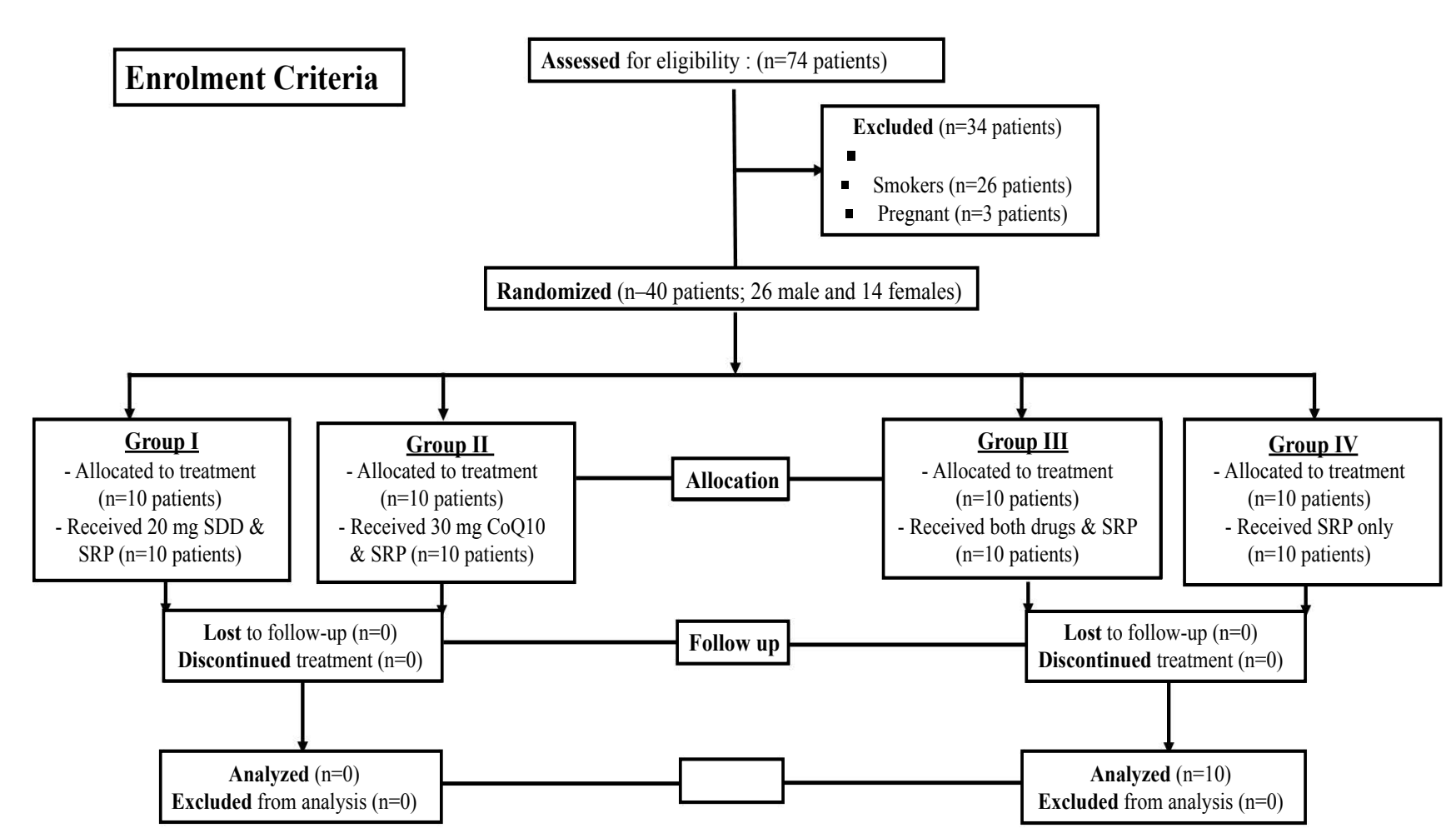

Figure 1: Flow chart of trial phases and enrolment criteria. All patients included in this study were instructed for performing proper oral hygiene techniques. SDD: Subantimicrobial Dose Doxycycline, SRP: Standard scaling and Root Planning, CoQ10: Co enzyme Q10. 
mesiobuccal aspect of each single rooted tooth, the maxillary canine, and left for 30 seconds. Then, the strips were placed immediately in $1.8 \mathrm{ml}$ Eppendorf tube containing $300 \mu \mathrm{l}$ phosphate buffered saline solution (Roche Applied Sciences, Canada, $\mathrm{pH}$ 6), $0.15 \mathrm{ml} \mathrm{NaCl}$ and $0.1 \%$ tween 20 as a preservative. Gingival crevicular fluid volume was determined by standardized weighing method [26]. Eppendorf tubes were stored at $-80^{\circ} \mathrm{C}$ until being analyzed [27].

\section{Clinical parameters}

After GCF sampling, the treatment modalities have been started as previously planned for each group. Clinical evaluation was performed by measuring gingival index (GI), plaque index (PI), bleeding index Table 1: Shows sociodemographic information of the 40 participants in this study.

\begin{tabular}{|c|c|}
\hline Variable & Number \\
\hline \multicolumn{2}{|l|}{ Age } \\
\hline $37-40$ years & 16 \\
\hline $41-50$ years & 20 \\
\hline $50-55$ years & 4 \\
\hline \multicolumn{2}{|l|}{ Sex } \\
\hline Male & 26 \\
\hline Female & 14 \\
\hline \multicolumn{2}{|l|}{ Marital status } \\
\hline Married & 27 \\
\hline Unmarried & 13 \\
\hline \multicolumn{2}{|l|}{ Number of kids } \\
\hline 0 & 3 \\
\hline $1-3$ & 23 \\
\hline$>3$ & 14 \\
\hline \multicolumn{2}{|l|}{ Education } \\
\hline Illiterate & 24 \\
\hline Intermediate & 11 \\
\hline High & 5 \\
\hline \multicolumn{2}{|l|}{ Occupation } \\
\hline Official worker & 5 \\
\hline Farmer & 23 \\
\hline None/retired & 7 \\
\hline \multicolumn{2}{|l|}{ Source of income } \\
\hline Owing farming & 9 \\
\hline Rental farming & 21 \\
\hline Employment & 3 \\
\hline Trading & 5 \\
\hline Others & 2 \\
\hline \multicolumn{2}{|l|}{ Residence } \\
\hline Urban & 7 \\
\hline Rural & 33 \\
\hline
\end{tabular}

(BI), probing pocket depth (PPD), and clinical attachment level $(\mathrm{CAL})$. The clinical parameters were recorded at baseline time (pretreatment), 1 month and 3 months post-treatment.

\section{Osteocalcin level in gingival crevicular fluid}

GCF samples were taken initially before treatment (baseline time) and at 1 month and 3 months after treatment. GCF osteocalcin level was analyzed using Elecsys N-MID Osteocalcin kit and electrochemiluminescence immunoassay analyzer (Elecsys 2010 Immunoassay System; Roche Diagnostics GmbH, Germany) following the manufacturer's recommendations.

\section{Statistical analysis}

Data were presented as means \pm standard deviation of the clinical parameters and osteocalcin level in GCF of the 4 treatment groups. Data were analyzed by one-way ANOVA where $\mathrm{P}$ value $<0.05$ was considered significant.

\section{Results}

The present study was carried out on 40 patients, free from any systemic diseases and randomly divided into 4 groups, 10 patients each. Table 1 shows patients' sociodemographic information. Improvement in all groups was based on the changes in the clinical parameters assessed when compared to the same parameter before treatment (baseline time). Mean values of clinical parameters in the 4 study groups at different time intervals were compared in tables 2-5. Significant $(\mathrm{P}<0.05)$ improvements in all clinical parameters at 3 months after treatment were evident when compared to their corresponding mean values at baseline time. There were significant $(\mathrm{P}<0.05)$ improvements of all clinical parameters at 3 months after treatment when compared to their corresponding mean values at 1 month after treatment with the exception of the bleeding index (BI) in group I (SRP plusdoxycycline), probing pocket depth (PPD) and clinical attachment level (CAL) in group II (SRP plusCoQ10). In addition, there were significant $(\mathrm{P}<0.05)$ improvements in all clinical parameters at 1 month after treatment when compared to their corresponding mean values at baseline time (Tables 2-5).

The inter-group comparison of the 4 groups at 1 month and 3 months post-treatment revealed the best significant improvements in the mean values of all clinical parameters of group III (SRP plus $20 \mathrm{mg}$ doxycycline plus $30 \mathrm{mg}$ CoQ10 twice/day for 3 months) as compared to other groups (Table 6,7 and Figure 2). Improvements in clinical parameters in the other 3 groups at 1 month and 3 months after different treatment modalities did not follow a consistent pattern favouring specific group, (Table 6,7 and Figure 2).

Mean values of osteocalcin levels in GCF of group III at 1 month and 3 months post-treatment was significantly higher $(\mathrm{P}<0.05)$ compared to the corresponding times in group I and IV but not group II. However, comparing the mean values of osteocalcin levels in GCF among groups I, II, and IV, at 1 month, 3 months posttreatment, revealed no significance (Table 8 and Figure 3). Increases

Table 2: Mean values \pm standard deviation of clinical parameters in group I treated with standard scaling and root planning plus $20 \mathrm{mg}$ doxycycline twice/day for 3 months. Letters a, b, and $c$ refer to the degree of significance at ${ }^{*} \mathrm{P}<0.05$; significant difference was found among groups marked by different letters ( $a$, b,c) and no significant difference was found among groups marked by similar letters.

\begin{tabular}{|l|l|l|l|l|l|}
\hline Time & Gingival Index & Plaque Index & Bleeding Index & Pocket Depth & Clinical Attachment Loss \\
\hline Baseline & $2.49 \pm 0.33^{\mathrm{a}}$ & $2.41 \pm 0.26^{\mathrm{a}}$ & $0.89 \pm 0.06^{\mathrm{a}}$ & $5.29 \pm 0.50^{\mathrm{a}}$ & $5.44 \pm 0.48^{\mathrm{a}}$ \\
\hline 1 Month & $0.66 \pm 0.14^{\mathrm{b}}$ & $0.65 \pm 0.11^{\mathrm{b}}$ & $0.37 \pm 0.14^{\mathrm{b}}$ & $4.34 \pm 0.61^{\mathrm{b}}$ & $4.44 \pm 0.53^{\mathrm{b}}$ \\
\hline 3 Months & $0.39 \pm 0.09^{\mathrm{c}}$ & $0.31 \pm 0.10^{\mathrm{c}}$ & $0.27 \pm 0.17^{\mathrm{b}}$ & $3.61 \pm 0.58^{\mathrm{c}}$ & $3.79 \pm 0.58^{\mathrm{c}}$ \\
\hline P Value & $0.00^{*}$ & $0.00^{*}$ & $0.00^{*}$ & $0.00^{*}$ & $0.00^{*}$ \\
\hline
\end{tabular}

Table 3: Mean values \pm standard deviation of clinical parameters in group II treated with standard scaling and root planning plus 30 mg CoQ10 twice/day for 3 months Letters $a, b$, and $c$ refer to the degree of significance at ${ }^{*} \mathrm{P}<0.05$; significant difference was found among groups marked by different letters (a,b,c) and no significant difference was found among groups marked by similar letters.

\begin{tabular}{|l|l|l|l|l|l|}
\hline Time & Gingival Index & Plaque Index & Bleeding Index & Pocket Depth & Clinical Attachment Loss \\
\hline Baseline & $2.17 \pm 0.27^{\mathrm{a}}$ & $2.07 \pm 0.32^{\mathrm{a}}$ & $0.77 \pm 0.13^{\mathrm{a}}$ & $4.57 \pm 0.44^{\mathrm{a}}$ & $4.79 \pm 0.52^{\mathrm{a}}$ \\
\hline 1 month & $0.62 \pm 0.17^{\mathrm{b}}$ & $0.67 \pm 0.17^{\mathrm{b}}$ & $0.36 \pm 0.12^{\mathrm{b}}$ & $3.75 \pm 0.45^{\mathrm{b}}$ & $3.8 \pm 0.42^{\mathrm{b}}$ \\
\hline 3 months & $0.26 \pm 0.06^{\mathrm{c}}$ & $0.22 \pm 0.08^{\mathrm{c}}$ & $0.1 \pm 0.04^{\mathrm{c}}$ & $3.4 \pm 0.37^{\mathrm{b}}$ & $3.39 \pm 0.40^{\mathrm{b}}$ \\
\hline P value & $0.000^{*}$ & $0.000^{*}$ & $0.000^{*}$ & $0.000^{*}$ & $0.000^{*}$ \\
\hline
\end{tabular}


Table 4: Mean values \pm standard deviations of clinical parameters in group III treated with standard scaling and root planning plus $20 \mathrm{mg}$ doxycycline and 30 mg CoQ10 twice/day for 3 months. Letters $a, b$, and $c$ refer to the degree of significance at ${ }^{*} \mathrm{P}<0.05$; significant difference was found among groups marked by different letters $(a, b, c)$ and no significant difference was found among groups marked by similar letters.

\begin{tabular}{|l|l|l|l|l|l|}
\hline Time & Gingival Index & Plaque Index & Bleeding Index & Pocket Depth \\
\hline Baseline & $2.42 \pm 0.3^{\mathrm{a}}$ & $2.36 \pm 0.38^{\mathrm{a}}$ & $0.85 \pm 0.08^{\mathrm{a}}$ & $4.55 \pm 0.43^{\mathrm{a}}$ & $4^{\mathrm{C}}$ \\
\hline 1 month & $0.42 \pm 0.08^{\mathrm{b}}$ & $0.42 \pm 0.1^{\mathrm{b}}$ & $0.26 \pm 0.14^{\mathrm{b}}$ & $3.37 \pm 0.4^{\mathrm{b}}$ \\
\hline 3 months & $0.27 \pm 0.04^{\mathrm{c}}$ & $0.27 \pm 0.07^{\mathrm{c}}$ & $0.07 \pm 0.02^{\mathrm{c}}$ & $2.74 \pm 0.4^{\mathrm{c}}$ \\
\hline P value & $0.000^{\star}$ & $0.000^{\star}$ & $0.000^{\star}$ & $0.000^{\mathrm{a}}$ & $2.72 \pm 0.4^{\mathrm{c}}$ \\
\hline
\end{tabular}

Table 5: Mean values \pm standard deviation of clinical parameters in group IV treated with standard scaling and root planning only. Letters a, $b$, and $c$ refer to the degree of significance at ${ }^{*} \mathrm{P}<0.05$; significant difference was found among groups marked by different letters $(a, b, c)$ and no significant difference was found among groups marked by similar letters.

\begin{tabular}{|l|l|l|l|l|l|}
\hline Time & Gingival Index & Plaque Index & Bleeding Index & Pocket Depth \\
\hline Baseline & $2.01 \pm 0.16^{\mathrm{a}}$ & $1.89 \pm 0.3^{\mathrm{a}}$ & $0.77 \pm 0.13^{\mathrm{a}}$ & $4.78 \pm 0.41^{\mathrm{a}}$ \\
\hline 1 month & $0.78 \pm 0.11^{\mathrm{b}}$ & $0.83 \pm 0.13^{\mathrm{b}}$ & $0.43 \pm 0.16^{\mathrm{b}}$ & $4.01 \pm 0.33^{\mathrm{b}}$ & $4.90 \pm 0.5^{\mathrm{a}}$ \\
\hline 3 months & $0.52 \pm 0.12^{\mathrm{c}}$ & $0.46 \pm 0.11^{\mathrm{c}}$ & $0.26 \pm 0.13^{\mathrm{c}}$ & $3.18 \pm 0.32^{\mathrm{b}}$ \\
\hline P value & $0.000^{\star}$ & $0.000^{\star}$ & $0.000^{\star}$ & $0.47^{\mathrm{c}}$ & $3.65 \pm 0.41^{\mathrm{c}}$ \\
\hline
\end{tabular}

Table 6: Inter-group comparison of the clinical parameters readings, mean values \pm standard deviation at 1 month after treatment. Letters a, $b$, and $c$ refer to the degree of significance at " $\mathrm{P}<0.05$; significant difference was found among groups marked by different letters (a,b,c) and no significant difference was found among groups marked by similar letters.

\begin{tabular}{|l|l|l|l|l|l|}
\hline Clinical Parameter & Group I & Group II & Group III & Group IV \\
\hline Gingival Index & $0.66 \pm 0.14^{\mathrm{ab}}$ & $0.62 \pm 0.17^{\mathrm{b}}$ & $0.42 \pm 0.08^{\mathrm{c}}$ & $0.78 \pm 0.11^{\mathrm{a}}$ \\
\hline Plaque Index & $0.65 \pm 0.11^{\mathrm{b}}$ & $0.67 \pm 0.17^{\mathrm{b}}$ & $0.41 \pm 0.1^{\mathrm{c}}$ & $0.83 \pm 0.13^{\mathrm{a}}$ \\
\hline Bleeding Index & $0.37 \pm 0.14^{\mathrm{ab}}$ & $0.36 \pm 0.12^{\mathrm{ab}}$ & $0.26 \pm 0.14^{\mathrm{b}}$ & $0.43 \pm 0.16^{\mathrm{a}}$ & $0.0001^{*}$ \\
\hline Pocket Depth & $4.34 \pm 0.61^{\mathrm{a}}$ & $3.75 \pm 0.45^{\mathrm{bc}}$ & $3.37 \pm 0.4^{\mathrm{c}}$ & 0.08 \\
\hline Clinical Attachment Loss & $4.44 \pm 0.53^{\mathrm{a}}$ & $3.8 \pm 0.42^{\mathrm{bc}}$ & $2.7 \pm 0.4^{\mathrm{c}}$ & $0.01 \pm 0.33^{\mathrm{ab}}$ & $4.18 \pm 0.32^{\mathrm{ab}}$ \\
\hline
\end{tabular}

Table 7: Inter-group comparison of the clinical parameters readings, mean values \pm standard deviation at 3 months after treatment. Letters a, b, and c refer to the degree of significance at ${ }^{\mathrm{P}} \mathrm{P}<0.05$; significant difference was found among groups marked by different letters $(a, b, c)$ and no significant difference was found among groups marked by similar letters.

\begin{tabular}{|l|l|l|l|l|}
\hline Clinical Parameter & Group I & Group II & Group III & Group IV \\
\hline Gingival Index & $0.39 \pm 0.09^{\mathrm{b}}$ & $0.26 \pm 0.06^{\mathrm{c}}$ & $0.27 \pm 0.04^{\mathrm{c}}$ & $0.52 \pm 0.12^{\mathrm{a}}$ \\
\hline Plaque Index & $0.31 \pm 0.10^{\mathrm{b}}$ & $0.22 \pm 0.08^{\mathrm{c}}$ & $0.27 \pm 0.07^{\mathrm{bc}}$ & $0.0001^{\star}$ \\
\hline Bleeding Index & $0.27 \pm 0.17^{\mathrm{a}}$ & $0.1 \pm 0.04^{\mathrm{b}}$ & $0.07 \pm 0.02^{\mathrm{b}}$ & $0.11^{\mathrm{a}}$ \\
\hline Pocket Depth & $3.61 \pm 0.58^{\mathrm{a}}$ & $3.40 \pm 0.37^{\mathrm{a}}$ & $2.74 \pm 0.4^{\mathrm{b}}$ & $0.0001^{\star}$ \\
\hline Clinical Attachment Loss & $3.79 \pm 0.58^{\mathrm{a}}$ & $3.39 \pm 0.40^{\mathrm{a}}$ & $2.72 \pm 0.4^{\mathrm{b}}$ & $3.61 \pm 0.47^{\mathrm{a}}$ \\
\hline
\end{tabular}

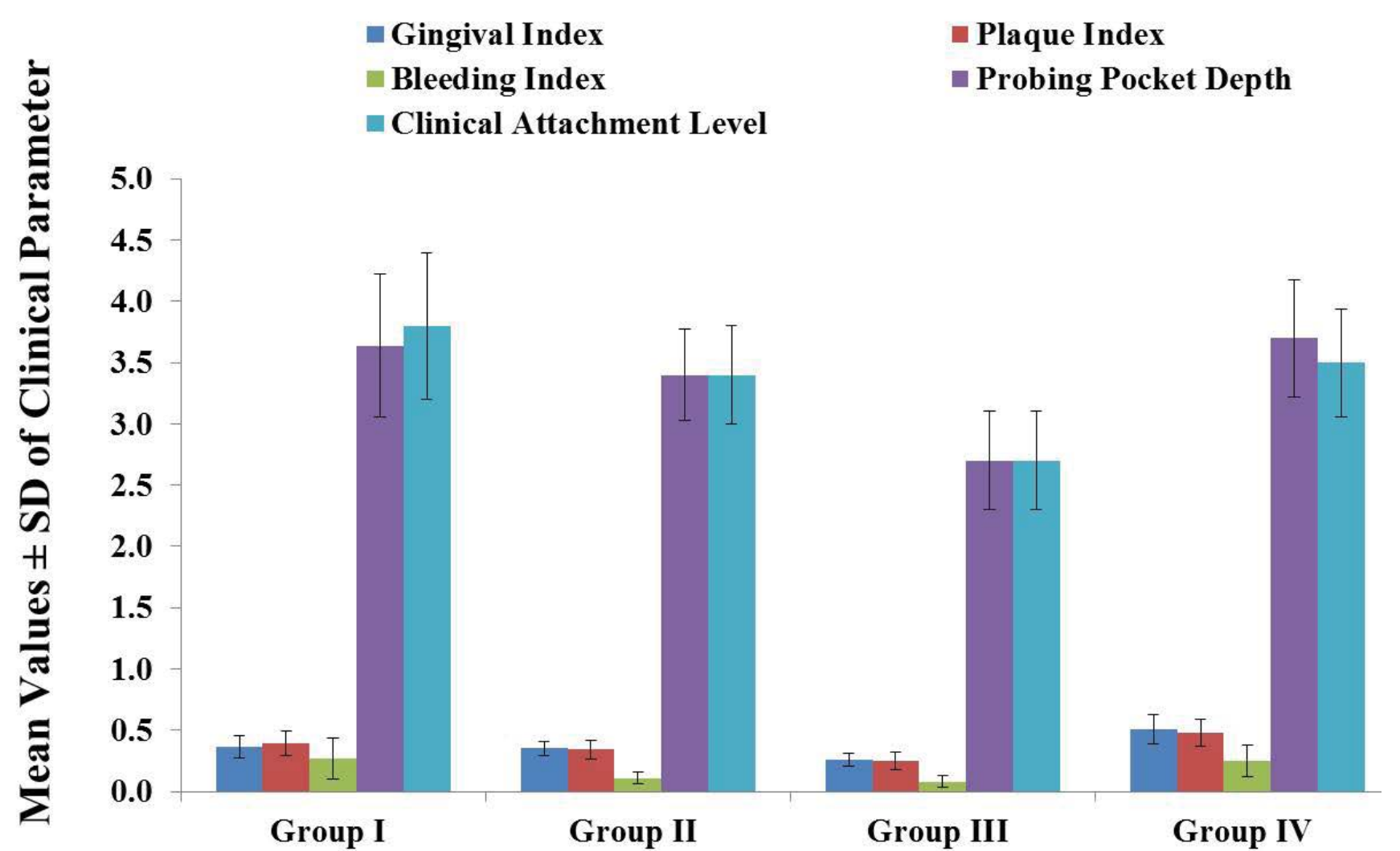

Figure 2: Inter-group comparison of the clinical parameters readings, mean values \pm standard deviation at 3 months after treatment. Group I treated with standard scaling and root planning plus $20 \mathrm{mg}$ doxycycline twice/day for 3 months; group II treated with standard scaling and root planning plus $30 \mathrm{mg}$ CoQ10 twice/day for 3 months; group III treated with standard scaling and root planning plus 20mg doxycycline and 30mg CoQ10 twice/day for 3 months; group IV treated with standard scaling and root planning only. For the degree of significance at $\mathrm{P}<0.05$ please refer to table 7 . 
Table 8: Mean values \pm standard deviation of osteocalcin levels in the gingival crevicular fluid (ng/ml) in Group I treated with standard scaling and root planning plus $20 \mathrm{mg}$ doxycycline twice/day for 3 months; group II treated with standard scaling and root planning plus $30 \mathrm{mg}$ CoQ10 twice/day for 3 months; group III treated with standard scaling and root planning plus 20 mg doxycycline and 30mg CoQ10 twice/day for 3 months; group IV treated with standard scaling and root planning only. Letters $a, b$, and $c$ refer to the degree of significance at ${ }^{*} \mathrm{P}<0.05$; significant difference was found among groups marked by different letters ( $\left.a, b, c\right)$ and no significant difference was found among groups marked by similar letters.

\begin{tabular}{|l|l|l|l|l|l|l|}
\hline Time & N & Group I & Group II & Group III & Group IV \\
\hline Baseline & 10 & $1.17 \pm 0.06^{\mathrm{b}}$ & $1.23 \pm 0.07^{\mathrm{ab}}$ & $1.27 \pm 0.12^{\mathrm{a}}$ & $1.147 \pm 0.04^{\mathrm{b}}$ \\
\hline 1 month & 10 & $1.11 \pm 0.08^{\mathrm{b}}$ & $1.17 \pm 0.08^{\mathrm{ab}}$ & $1.27 \pm 0.23^{\mathrm{a}}$ & $0.03^{\star}$ & $1.12 \pm 0.06^{\mathrm{b}}$ \\
\hline 3 months & 10 & $1.1 \pm 0.09^{\mathrm{b}}$ & $1.17 \pm 0.08^{\mathrm{ab}}$ & $1.26 \pm 0.20^{\mathrm{a}}$ & $0.04^{\star}$ \\
\hline P value & & 0.14 & 0.20 & 0.98 & $1.12 \pm 0.06^{\mathrm{b}}$ \\
\hline
\end{tabular}

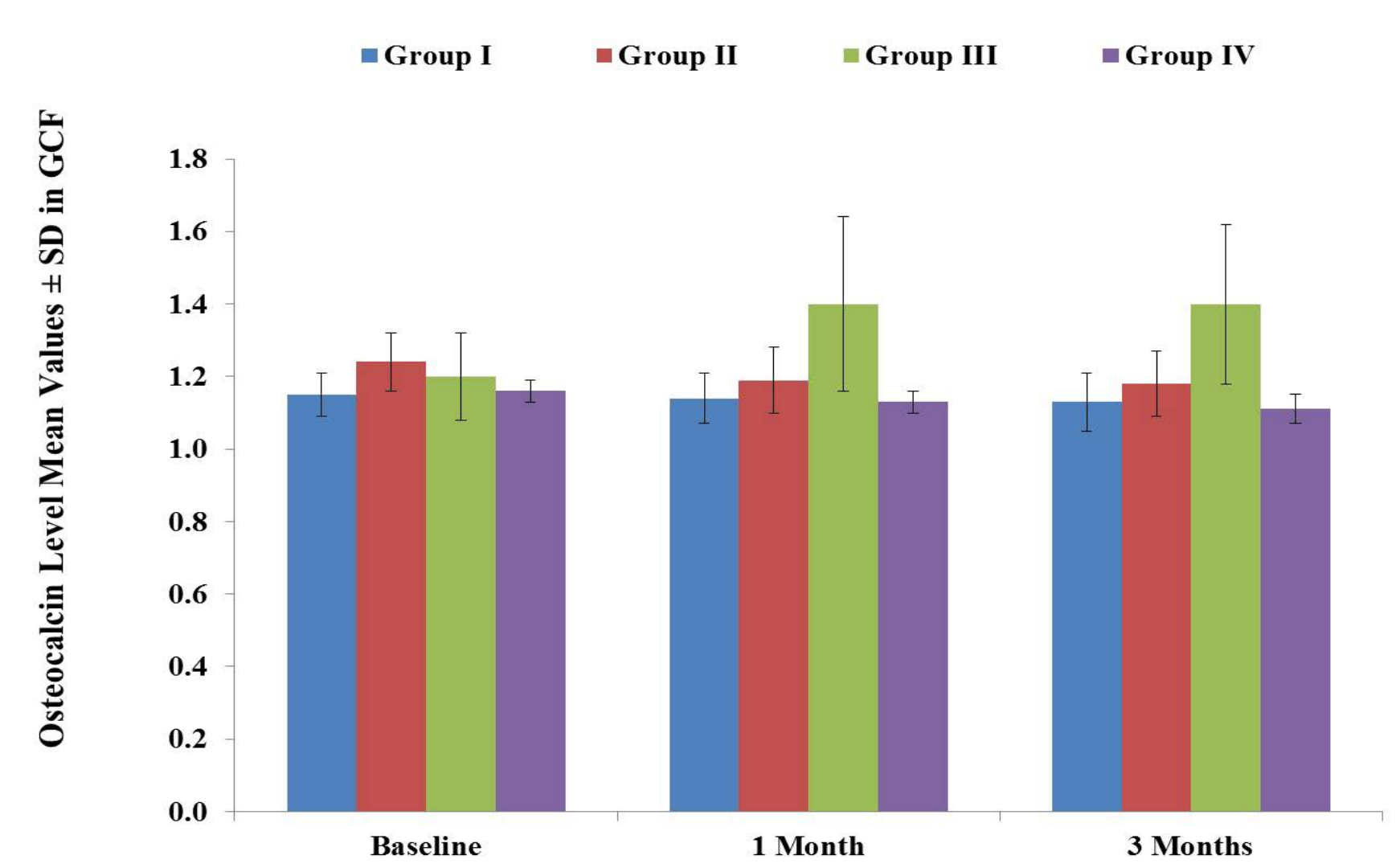

Figure 3: Mean values \pm standard deviation of osteocalcin levels in the gingival crevicular fluid (ng/ml) in Group I treated with standard scaling and root planning plus 20mg doxycycline twice/day for 3 months; group II treated with standard scaling and root planning plus $30 \mathrm{mg}$ CoQ10 twice/day for 3 months; group III treated with standard scaling and root planning plus $20 \mathrm{mg}$ doxycycline and $30 \mathrm{mg}$ CoQ10 twice/day for 3 months; group IV treated with standard scaling and root planning only. For the degree of significance at $\mathrm{P}<0.05$ please refer to table 8 .

in osteocalcin levels in group III at 1 month and 3 months were not significant when compared to baseline time and to each other. Mean values of osteocalcin levels in GCF of group III had a strong negative correlations (linear dependence) with the mean values of the clinical parameters throughout the study; Pearson's correlation coefficients were $-1,-1,-0.97,-0.93$, and -0.94 with the gingival index, plaque index, bleeding index, probing pocket depth, and clinical attachment level, respectively.

\section{Discussion}

This study demonstrated that administration of subantimicrobial dose doxycycline or Coenzyme Q10 twice/day for 3 months, for treatment of chronic periodontitis, resulted in significant improvement in the clinical parameters compared to that achieved by standard scaling and root planning alone. Moreover, treatment of chronic periodontitis by combination of both drugs twice/day for 3 months showed even better therapeutic effect compared to that achieved by either drug alone. We observed strong negative correlation between osteocalcin levels in GCF and the clinical parameters when a combination of both drugs was used. Standard scaling and root planning and oral hygiene measures were performed in the four groups. Thus, the pathogenic burden to the gingival and periodontal tissues has been eliminated or at least minimized. Accordingly, resolution of gingival inflammation, marked reduction in the bleeding index, and the probing pocket depth, in addition to marked increase of clinical attachment level were observed in all groups, especially in both drugs combination group (group III). However, the bleeding index in group I (SRP plusdoxycycline), probing pocket depth and clinical attachment level in group II (SRP plus CoQ10) haveimproved but did not reach significant levels. Subantimicrobial dose doxycycline (SDD) treatement group showed satisfactory clinical improvement at 1 and 3 months post-treatment compared to baseline time. This improvement might not be attributed only to SRP and proper oral hygiene measures maintained by the patient, but also to the host modulatory effect of SDD on the periodontal tissues that was maintained for 3 months. Walker et al. [28] stated that SDD has antiinflammatory and anti-collagenase effects that enhance the healing of periodontal tissues. Besides, Golub et al. [9] reported that SDD inhibits connective tissue destruction through direct inhibition of MMPs in gingival tissues and inhibits bone resorption via regulation of osteoclast function. Additionally, SDD inhibits the activation of MMPs precursors [10]. SDD has high affinity to bone and soft tissues, thus, its accumulation in the periodontium would further enhance its curative effect [15]. Chio et al. [8] reported similar results after administration of SDD that was associated with significant decrease in MMP-8 level in their patients' GCF.

Improvement in clinical parameters in the second group, treated with CoQ10, is partly caused by the antioxidant effect of CoQ10 
that minimized tissue destruction by removal of free radicals and maintaining the cellular energy [29]. CoQ10 has favourable effect on the endothelial cells lining the blood vessels [18] and partial bacteriostatic effect on subgingival microorganisms [30]. In addition, CoQ10 increases the phagocytic activity of macrophages, proliferation of granulocytes in response to experimental infections, increases CD4/CD8 ratios and IgG levels, and improves oxygen utilization in the gingival cells [10,31]. Babbush et al. [19] and MatthewsBrzozowska et al. [32] reported decreased gingival bleeding, pain and itching in patients with gingivitis and periodontitis, respectively, following administration of CoQ10. In addition, Hanioka et al. [33] reported remarkable reduction in the pocket depth when used topical CoQ10 in combination with mechanical debridement. Furthermore, topical perioQ gel (CoQ10) has been reported to improve plaque, gingival, and bleeding indices, pocket depth, and clinical attachment levelwhen used in combination with SRP in chronic periodontitis patients $[34,35]$.

The best improvement in clinical parameters $(\mathrm{P}<0.05)$ shown in this study was seen in patients treated with a combination of SDD and CoQ10 at 1 and 3 months post-treatment compared to baseline time. Therefore, SDD and CoQ10 might synergistically act to further reduce and/or regulate the inflammatory process taking place in the periodontal tissues.

Osteocalcin is synthesized by osteoblasts and its serum level is considered as a marker of bone formation [21]. Osteocalcin level in gingival crevicular fluid (GCF) was suggested to reflect inflammation in periodontitis and was studied as a potential marker of bone turnover in periodontal diseases [36]. In this study, we analyzed osteocalcin levels in GCF rather than serum or saliva because GCF is believed to be an inflammatory exudate related to different episodes of periodontitis [24]. We collected GCF by using an intra-crevicular technique as a quick, easy and least traumatic approach [37] by running an electrochemiluminescent immunoassay, an accurate and sensitive immunoassay. Although, osteocalcin levels were minimally decreased along this study in groups I, II, and IV, no significant differences were found among values at 3 months post-treatment compared to either baseline time or 1 month post-treatment. However, in group III, treated with a combination of SDD and CoQ10, osteocalcin levels increased at 1 and 3 months post-treatment but were not significant There were strong negative correlations between the values of clinical parameters and the increase in osteocalcin levels in GCF. The reason for minimal changes observed in GCF osteocalcin levels might be due to the short-term study period ( 3 months) that did not allow sufficient bone formation to occur, which, in term, affects the GCF osteocalcin levels. Golub et al. [24] reported no reduction in osteocalcin levels in GCF with SDD (20mg twice/day) administered for 2 months. In contrast to our findings, Giannobile et al. [21] reported a strong correlation between GCF osteocalcin levels and active bone turnover. On the other hand, Giannobile et al. [36] concluded that, osteocalcin as a specific marker of bone turnover, might not be a good predictive indicator in periodontal disease.

This study shows some limitations that includes small sample size in total and per group and short time of follow up (3 months) The present study was carried out under ideal clinical conditions with strict selection criteria that excluded many patients at risk, such as; smokers and medically compromised patients. These conditions limited the number of patients recruited and the overall observation period. However, this preliminary randomized controlled clinical trial provided valuable information on the applicability of using different treatment modalities for the management of chronic periodontitis. The findings of this study could have some merits to the clinicians and might help them to choose the best option for patients with similar clinical situations.

\section{Conclusion}

In chronic periodontitis, administration of SDD or CoQ10 twice/ day for 3 months, as an adjuvant to SRP, significantly improved the clinical parameters when compared to SRP alone. A combination of both drugs twice/day for 3 months is of better therapeutic value compared to that of either drug alone. Treatment modalities in this study did not show significant reduction in GCF osteocalcin levels however, a combination of both drugs showed increases in osteocalcin levels at 1 and 3 months post-treatment that were not significant either. Accordingly, further investigations on larger population groups for extended time intervals (more than 3 months) are recommended to further explore the exact role of osteocalcin in periodontal diseases and its relation to different treatment modalities.

\section{Ethical Statement}

No conflict of interest exists. This study followed the Declaration of Helsinki on medical protocol and ethics and was approved by the regional Ethical Review Board of Mansoura University.

\section{Acknowledgements}

The authors would like to thank Mansoura University and the Egyptian Ministry of Higher Education and Scientific Research for funding.

\section{References}

1. Baelum V, Lopez R (2004) Periodontal epidemiology: towards social science or molecular biology? Community Dent Oral Epidemiol 32: 239-249.

2. Pussinen PJ, Paju S, Mäntylä P, Sorsa T (2007) Serum microbial- and hostderived markers of periodontal diseases: a review. Curr Med Chem 14: 2402 2412.

3. Kim TS, Schenk A, Lungeanu D, Reitmeir P, Eickholz P (2007) Nonsurgical and surgical periodontal therapy in single-rooted teeth. Clin Oral Investig 11: 391-399.

4. Ryan ME (2002) Clinical applications for host modulatory therapy. Compend Contin Educ Dent 23: 1071-1076.

5. Reddy MS, Geurs NC, Gunsolley JC (2003) Periodontal host modulation with antiproteinase, anti-inflammatory, and bone-sparing agents. A systematic review. Ann Periodontol 8: 12-37.

6. Sorsa T, Tjäderhane L, Konttinen YT, Lauhio A, Salo T, et al. (2006) Matrix metalloproteinases: contribution to pathogenesis, diagnosis and treatment of periodontal inflammation. Ann Med 38: 306-321.

7. Ashley RA (1999) Clinical trials of a matrix metalloproteinase inhibitor in human periodontal disease. SDD Clinical Research Team. Ann N Y Acad Sci 878: 335-346.

8. Choi DH, Moon IS, Choi BK, Paik JW, Kim YS, et al. (2004) Effects of sub-antimicrobial dose doxycycline therapy on crevicular fluid MMP-8, and gingival tissue MMP-9, TIMP-1 and IL-6 levels in chronic periodontitis. J Periodontal Res 39: 20-26.

9. Golub LM, Evans RT, McNamara TF, Lee HM, Ramamurthy NS (1994) A non-antimicrobial tetracycline inhibits gingival matrix metalloproteinases and bone loss in Porphyromonas gingivalis-induced periodontitis in rats. Ann N Y Acad Sci 732: 96-111.

10. Rifkin BR, Vernillo AT, Golub LM (1993) Blocking periodontal disease progression by inhibiting tissue-destructive enzymes: a potential therapeutic role for tetracyclines and their chemically-modified analogs. J Periodontol 64: 819-827.

11. Novak MJ, Johns LP, Miller RC, Bradshaw MH (2002) Adjunctive benefits of subantimicrobial dose doxycycline in the management of severe, generalized, chronic periodontitis. J Periodontol 73: 762-769.

12. Emingil G, Gürkan A, Atilla G, Berdeli A, Cinarcik S (2006) Adjunctive lowdose doxycycline therapy effect on clinical parameters and gingival crevicular fluid tissue plasminogen activator levels in chronic periodontitis. Inflamm Res 55: 550-558.

13. Tüter G, Serdar M, Kurtis B, Walker S, Atak A, et al. (2010) Effects of scaling and root planing and subantimicrobial dose doxycycline on gingival crevicular fluid levels of matrix metalloproteinase-8,-13 and serum levels of HsCRP in patients with chronic periodontitis. J Periodontol 81: 1132-1139.

14. Greenstein G (2004) Efficacy of subantimicrobial-dose doxycycline in the treatment of periodontal diseases: a critical evaluation. Int J Periodontics Restorative Dent 24: 528-543.

15. Preshaw PM, Hefti AF, Novak MJ, Michalowicz BS, Pihlstrom BL, et al (2004) Subantimicrobial dose doxycycline enhances the efficacy of scaling and root planing in chronic periodontitis: a multicenter trial. J Periodontol 75: 1068-1076.

16. Salvi GE, Lang NP (2005) Host response modulation in the management of periodontal diseases. J Clin Periodontol 32: 108-129.

17. Shizukuishi S, Hanioka T, Tsunemitsu A, Fukunaga $\mathrm{Y}$, Kishi $\mathrm{T}$, et al (1986) Evaluation of oxygen utilization in gingiva by tissue reflectance spectrophotometry. In: Folkers K, Yamamura, Y (eds) Biomedical and Clinical Aspects of Coenzyme Q Vol 5, Elsevier: Amsterdam. 359-368. 
18. Kaikkonen J, Nyyssönen K, Porkkala-Sarataho E, Poulsen HE, Metsä-Ketelä T, et al. (1997) Effect of oral coenzyme Q10 supplementation on the oxidation resistance of human VLDL+LDL fraction: absorption and antioxidative properties of oil and granule-based preparations. Free Radic Biol Med 22: 1195-1202.

19. Babbush CA, Kagan D, Madhavi D, Rubido A (2010) The Efficacy of Perfect Smile Toothpaste Containing Coenzyme Q10-b-Cyclodextrin Inclusion Complex in Reducing Mild to Moderate Gingivitis. Nat Med J 2: 16-20.

20. Price PA, Lothringer JW, Baukol SA, Reddi AH (1981) Developmenta appearance of the vitamin K-dependent protein of bone during calcification. Analysis of mineralizing tissues in human, calf, and rat. J Biol Chem 256 3781-3784.

21. Giannobile WV, Lynch SE, Denmark RG, Paquette DW, Fiorellini JP, et al. (1995) Crevicular fluid osteocalcin and pyridinoline cross-linked carboxyterminal telopeptide of type I collagen (ICTP) as markers of rapid bone turnover in periodontitis. A pilot study in beagle dogs. J Clin Periodontol 22: $903-910$.

22. Bullon P, Goberna B, Guerrero JM, Segura JJ, Perez-Cano R, et al. (2005) Serum, saliva, and gingival crevicular fluid osteocalcin: their relation to periodontal status and bone mineral density in postmenopausal women. $J$ Periodontol 76: 513-519.

23. Ozçaka O, Nalbantsoy A, Buduneli N (2011) Salivary osteocalcin levels are decreased in smoker chronic periodontitis patients. Oral Dis 17: 200-205.

24. Golub L, Lee H, Greenwald R, Ryan M, Sorsa T, et al. (1997) A matrix metalloproteinase inhibitor reduces bone-type collagen degradation fragments and specific collagenases in gingival crevicular fluid during adult periodontitis. J Inflamm Res 46: 310-319.

25. Armitage GC (1999) Development of a classification system for periodontal diseases and conditions. Ann Periodontol 4: 1-6.

26. Ginnopoulou C (1988) Can crevicular fluid component analysis assist in diagnosis and monitoring periodontal breakdown? In: Guggenheim B (ed) Periodontology Today, International congress, Basel: Karger, Zurich 260-270.

27. Avellan NL, Sorsa T, Tervahartiala T, Mäntylä P, Forster C, et al. (2005) Painful tooth stimulation elevates matrix metalloproteinase-8 levels locally in human gingival crevicular fluid. J Dent Res 84: 335-339.
28. Walker C, Thomas J, Nangó S, Lennon J, Wetzel J, et al. (2000) Long-term treatment with subantimicrobial dose doxycycline exerts no antibacterial effect on the subgingival microflora associated with adult periodontitis. J Periodontol 71: 1465-1471.

29. Prakash S, Sunitha J, Hans M (2010) Role of coenzyme $Q(10)$ as an antioxidant and bioenergizer in periodontal diseases. Indian J Pharmacol 42: $334-337$

30. McRee JT, Hanioka T, Shizukuishi S, Folkers K (1993) Therapy with Coenzyme Q10 for patients with periodontal disease. 1. Effect of Coenzyme Q10 on subgingival micro-organisms. J Dent Health 43: 659-666.

31. Saiki I, Tokushima Y, Nishimura K, Azuma I (1983) Macrophage activation with ubiquinones and their related compounds in mice. Int $\mathrm{J}$ Vitam Nutr Res 53: 312-320.

32. Matthews-Brzozowska T, Kurhanska-Flisykowska A, WyganowskaSwiatkowska M, Stopa J (2007) Healing of periodontal tissue assisted by Coenzyme Q10 with Vitamin E: Clinical and laboratory evaluation. Pharmacol Rep 59: 257-260.

33. Hanioka T, Tanaka M, Ojima M, Shizukuishi S, Folkers K (1994) Effect of topical application of coenzyme Q10 on adult periodontitis. Mol Aspects Med 15: s241-248.

34. Sale ST, Parvez H, Yeltiwar RK, Vivekanandan G, Pundir AJ, et al. (2014) A comparative evaluation of topical and intrasulcular application of coenzyme Q10 (Perio $Q^{\mathrm{TM}}$ ) gel in chronic periodontitis patients: A clinical study. J Indian Soc Periodontol 18: 461-465.

35. Hans M, Prakash S, Gupta S (2012) Clinical evaluation of topical application of perio-Q gel (Coenzyme $Q(10)$ ) in chronic periodontitis patients. J Indian Soc Periodontol 16: 193-199.

36. Giannobile WV, Al-Shammari KF, Sarment DP (2003) Matrix molecules and growth factors as indicators of periodontal disease activity. Periodontol 2000 31: 125-134.

37. Griffiths GS (2003) Formation, collection and significance of gingival crevice fluid. Periodontol 2000 31: 32-42. 